\title{
Comparative study of saline infusion sonography and hysteroscopy for evaluation of uterine cavity in abnormal uterine bleeding
}

\author{
Sowjanya Nallapati, P. Pallavee*, Seetesh Ghose
}

\begin{abstract}
Department of Obstetrics \& Gynecology, Mahatma Gandhi Medical College \& Research Institute, Pillaiyarkuppam, Pondicherry-607402, India
\end{abstract}

Received: 23 April 2015

Accepted: 10 May 2015

*Correspondence:

Dr. P. Pallavee,

E-mail: ppallavee@ rediffmail.com

Copyright: (c) the author(s), publisher and licensee Medip Academy. This is an open-access article distributed under the terms of the Creative Commons Attribution Non-Commercial License, which permits unrestricted non-commercial use, distribution, and reproduction in any medium, provided the original work is properly cited.

\begin{abstract}
Background: Intra-cavitary uterine pathology is the commonest cause of abnormal uterine bleeding. Hysteroscopy is considered as the gold standard for uterine cavity examination. However, in resource limited set-ups saline infusion sonography is an effective alternative to hysteroscopy. The current study aims to compare the accuracy of saline infusion sonography with hysteroscopy in identifying intra-cavitary lesions in women with abnormal uterine bleeding. Methods: 52 patients with abnormal uterine bleeding underwent saline infusion sonography followed by hysteroscopy. The parameters studied were endometrial thickness, presence of sub-mucosal fibroid and endometrial polyp.

Results: Upon comparison of saline infusion sonography with hysteroscopy, for detecting endometrial hyperplasia the sensitivity, specificity, positive and negative predictive value were $100 \%, 94 \%, 40 \%$ and $100 \%$ respectively. For endometrial polyp the sensitivity, specificity, positive and negative predictive values were $90.90 \%, 92.68 \%, 76.92 \%$ and $97.43 \%$ respectively. Similarly, the sensitivity, specificity, positive and negative predictive values for submucosal fibroid were $86.36 \%, 83 \%, 79.16 \%$ and $89.28 \%$ respectively.

Conclusions: Saline infusion sonography is a less invasive alternative to hysteroscopy for diagnosis of intra-cavitary lesions in women with abnormal uterine bleeding.
\end{abstract}

Keywords: Saline infusion sonography, Hysteroscopy, Abnormal uterine bleeding, Uterine cavity abnormalities

\section{INTRODUCTION}

Abnormal uterine bleeding is one of the main reasons for women to consult a gynecologist. Approximately $33 \%$ of all admissions to gynecology clinics are due to abnormal uterine bleeding. ${ }^{1}$ Confirming the diagnosis and planning the treatment of abnormal uterine bleeding is very important in clinical practice. It is essential to distinguish organic causes from functional causes. Although dysfunctional causes require medical treatment, organic causes such as endometrial polyp, uterine fibroid, endometrial hyperplasia and endometrial cancer may require surgical treatment. Transvaginal ultrasonography is highly applicable, non-invasive and preferred initially in evaluation of women with abnormal uterine bleeding., ${ }^{2,3}$ However, the accuracy of transvaginal sonography is limited in the diagnosis of focal endometrial lesions. This can be overcome by saline infusion sonography, which can be performed easily and rapidly and is well tolerated by patients. It can accurately differentiate focal endometrial lesions and provide information about the localization and the extent of subendometrial lesions affecting the uterine cavity. ${ }^{4,5}$ Hysteroscopy is an effective procedure, but is more expensive than Saline Infusion Sonography (SIS). Direct visualization of uterine cavity is possible by hysteroscopy but it does not give any information about myometrium and adnexa. The aim of this study was to compare the diagnostic accuracy of SIS with the gold standard, 
hysteroscopy for detecting intra-cavitary abnormalities in women with abnormal uterine bleeding.

\section{METHODS}

This comparative study was conducted after obtaining clearance from Hospital Ethics Committee. 52 women in the age group of 25 to 55 years, who complained of abnormal uterine bleeding and did not respond to conventional medical therapy, were recruited for the study after taking informed consent. Of these, only 52 patients underwent both SIS and hysteroscopy. Bleeding due to coagulopathies, patients with past history of malignancy, pregnancy or suspecting pregnancy, bleeding due to systemic diseases and women with active pelvic infections were excluded from this study.

A detailed history was taken with special attention towards the menstrual history regarding onset, course, duration and flow. A complete general examination followed by local examination to assess uterine size, position, mobility, any adnexal mass and tenderness or presence of any cervical mass was determined. Patients who satisfied inclusion and exclusion criteria were included in the study and informed consent was taken from them.

SIS was done for the patients in the postmenstrual phase. Conventional transvaginal sonography of the uterus was performed in both sagittal and oblique transverse planes with the $7.5 \mathrm{MHz}$ probe (PHILIPS HD 7). Subsequently, maintaining asepsis a No.8 Foley's catheter was passed through the cervix into the uterine cavity without dilating the cervix or use of any local anesthesia.The balloon was inflated to fix the catheter into the cavity to provide stable filling and prevent backflow of saline. About 10-15 ml of $0.9 \%$ saline was instilled slowly into the endometrial cavity to provide hypoechogenic contrast to get optimal visualization of abnormal structures. Transvaginal probe was reinserted to look for endometrial pathology like polyp and sub-mucosal fibroid and to measure the endometrial thickness.

Following SIS, all patients were subjected to hysteroscopy using rigid, continuous flow hysteroscopy of 2.9 Fr (PROMIS, Germany). If there was any intrauterine pathology, the shape, size and site of it was noted. At the end of the procedure, the hysteroscope was slowly withdrawn through the cervical canal to visualize and detect any intra-cervical pathology. Operative hysteroscopy was done immediately whenever it was needed.

Parameters studied were the presence of endometrial hyperplasia, sub-mucosal fibroid or an endometrial polyp. Data was entered separately for SIS and hysteroscopy and analyzed. The sensitivity, specificity, positive and negative predictive values were calculated.

\section{RESULTS}

In the present study, mean age of women with abnormal uterine bleeding was 43 years. Of these, $27(51.9 \%)$ women belonged to the age group of 40-50 years. Majority of women were multiparous, accounting for $90.38 \%$ of the study population and belonged to low socio-economic status. Among them 18 (34.61\%) had menorrhagia, 17(32.69\%) had metrorrhagia, $11(21.15 \%)$ had meno-metrorrhagia and 4 (7.69\%) had other menstrual disturbances. Only 2 women had dysmenorrhea $(3.84 \%)$ (Table 1$)$.

Table 1: Patient profile.

\begin{tabular}{|c|c|c|}
\hline & $\begin{array}{l}\text { No. of } \\
\text { patients }\end{array}$ & $\begin{array}{l}\text { Percentage } \\
(\%)\end{array}$ \\
\hline \multicolumn{3}{|c|}{ Age group (years) } \\
\hline $20-30$ & 1 & $1.92 \%$ \\
\hline $30-40$ & 13 & $25 \%$ \\
\hline $40-50$ & 27 & $51.93 \%$ \\
\hline $50-60$ & 11 & $21.15 \%$ \\
\hline Total & 52 & $100 \%$ \\
\hline \multicolumn{3}{|l|}{ Parity } \\
\hline Nulligravida & 1 & $1.93 \%$ \\
\hline Primipara & 4 & $7.69 \%$ \\
\hline Multipara & 47 & $90.38 \%$ \\
\hline Total & 52 & $100 \%$ \\
\hline \multicolumn{3}{|c|}{ Socio economic status (SES) } \\
\hline I & 0 & 0 \\
\hline II & 3 & $5.76 \%$ \\
\hline III & 15 & $28.84 \%$ \\
\hline IV & 18 & $34.64 \%$ \\
\hline $\mathrm{V}$ & 16 & $30.76 \%$ \\
\hline Total & 52 & $100 \%$ \\
\hline
\end{tabular}

Among the 52 women who underwent saline infusion sonography, $10(19.23 \%)$ had normal endometrium, 5 $(9.61 \%)$ had endometrial hyperplasia, endometrial polyps were seen in $12(23.07 \%)$ and $25(48.07 \%)$ had submucosal fibroids. Hysteroscopy was performed in all these women and normal cavities were found in 17 $(32.69 \%)$, endometrial hyperplasia in 2 (3.84\%), endometrial polyp in $11(21.15 \%)$ and sub-mucosal fibroid in $22(42.30 \%)$ (Table 2$)$.

Table 2: Comparison of saline infusion sonography with hysteroscopy.

\begin{tabular}{|lll|}
\hline Findings & SIS $(\%)$ & $\begin{array}{l}\text { Hysteroscopy } \\
(\%)\end{array}$ \\
\hline Normal & $10(19.23)$ & $17(32.69)$ \\
\hline Endometrial hyperplasia & $5(9.61)$ & $2(3.84)$ \\
\hline Endometrial polyp & $12(23.07)$ & $11(21.15)$ \\
\hline Sub mucosal fibroid & $25(48.07)$ & $22(42.30)$ \\
\hline Total & $52(100)$ & $52(100)$ \\
\hline
\end{tabular}


The sensitivity, specificity, positive and negative predictive values of saline infusion sonography to detect endometrial hyperplasia in comparison to hysteroscopy were $100 \%, 94 \%, 40 \%$ and $100 \%$ respectively. The sensitivity, specificity, positive and negative predictive values to detect endometrial polyps were $90.90 \%$, $92.68 \%, 76.92 \%$ and $97.43 \%$ respectively. Similarly, the sensitivity, specificity, positive and negative predictive value of saline infusion sonography in comparison to hysteroscopy for detecting sub-mucosal fibroid was $86.36 \%, 83 \%, 79.16 \%$ \& $89.28 \%$ respectively (Table 3 ).

Table 3: Test validation of SIS with hysteroscopy.

\begin{tabular}{|lllll|}
\hline & Sensitivity & Specificity & PPV & NPV \\
\hline $\begin{array}{l}\text { Endometrial } \\
\text { hyperplasia }\end{array}$ & $100 \%$ & $94 \%$ & $40 \%$ & $100 \%$ \\
\hline $\begin{array}{l}\text { Endometrial } \\
\text { polyp }\end{array}$ & $90.90 \%$ & $92.68 \%$ & $76.92 \%$ & $97.43 \%$ \\
\hline $\begin{array}{l}\text { Sub- } \\
\text { mucosal } \\
\text { fibroid }\end{array}$ & $86.36 \%$ & $83 \%$ & $79.16 \%$ & $89.28 \%$ \\
\hline
\end{tabular}

\section{DISCUSSION}

In the present study we evaluated the diagnostic accuracy of saline infusion sonography with reference to the current gold standard hysteroscopy for detecting intrauterine pathology in women with abnormal uterine bleeding. More than $40 \%$ of women with abnormal uterine bleeding have some intrauterine pathology. ${ }^{6} \mathrm{~A}$ systematic review by Farquhar $\mathrm{C}$ et al. ${ }^{7}$ on investigations for abnormal uterine bleeding in premenopausal women using transvaginal sonography, saline infusion sonography and hysteroscopy showed that the most common abnormalities detected were sub-mucosal fibroids, endometrial polyps and endometrial hyperplasia. We used these three pathologies to assess the diagnostic accuracy of saline infusion sonography in comparison to hysteroscopy. We observed that majority of women with abnormal uterine bleeding belonged to the age group of $40-50$ years $(51.9 \%)$ and the commonest bleeding pattern was menorrhagia (34.6\%). Various other studies have also reported menorrhagia as the most common menstrual abnormality due to some intrauterine pathology in premenopausal women during their $3^{\text {rd }}$ or $4^{\text {th }}$ decades of life. ${ }^{8,9}$

In our study, we found 10 normal cavities during saline infusion sonography, which were also found to be normal during hysteroscopy. Intra-cavitary anatomical cause was found in $80.7 \%$ women with SIS and $67.2 \%$ in hysteroscopy which reasserts the need for early evaluation of uterine cavity in women who are not responding well to medical management for abnormal uterine bleeding. The most common abnormality detected in both saline infusion sonography and hysteroscopy was sub-mucosal fibroid. Haemila et al. ${ }^{9}$ and Rudra et al. ${ }^{10}$ also found sub mucous fibroid as the predominant lesion associated with abnormal uterine bleeding in both pre and post-menopausal women.

Our findings of various lesions in saline infusion sonography were endometrial hyperplasia (9.6\%), endometrial polyp $(23.1 \%)$ and sub-mucosal fibroid (48.1\%). Subsequently, diagnostic hysteroscopy showed endometrial hyperplasia in $3.8 \%$, endometrial polyp in $32.7 \%$ and sub-mucosal fibroid in $42.3 \%$. Among the various lesions, endometrial hyperplasia was most accurately detected using SIS with a sensitivity of $100 \%$ and specificity of $94 \%$. This finding is reflected in other studies as shown in Table 4..$^{9,11,12}$ The least sensitivity for detection with saline infusion sonography was for submucosal fibroids. 5 patients were diagnosed with submucosal fibroids during SIS. However, two of them were found to have polyp and three had normal cavities on diagnostic hysteroscopy.

Table 4: Diagnostic accuracy of SIS for various endometrial pathology.

\begin{tabular}{|c|c|c|c|c|c|}
\hline Pathology & & Our study & Rudra et al. ${ }^{8}$ & Btosis et al. ${ }^{10}$ & Dasgupta et al. ${ }^{11}$ \\
\hline \multirow{2}{*}{$\begin{array}{l}\text { Endometrial } \\
\text { hyperplasia }\end{array}$} & Sensitivity & $100 \%$ & $97.9 \%$ & - & 88 \\
\hline & Specificity & $94 \%$ & $100 \%$ & - & $90.6 \%$ \\
\hline \multirow{2}{*}{$\begin{array}{l}\text { Endometrial } \\
\text { polyp }\end{array}$} & Sensitivity & $90.9 \%$ & $97.3 \%$ & $96 \%$ & $97.6 \%$ \\
\hline & Specificity & $92.6 \%$ & $93 \%$ & $96 \%$ & $97.6 \%$ \\
\hline \multirow{2}{*}{$\begin{array}{l}\text { Sub mucosal } \\
\text { fibroid }\end{array}$} & Sensitivity & $86.36 \%$ & $97.3 \%$ & $99 \%$ & $98.7 \%$ \\
\hline & Specificity & $83 \%$ & $88.2 \%$ & $88 \%$ & $85.7 \%$ \\
\hline
\end{tabular}

Overall, the diagnostic accuracy for detecting intracavitary abnormalities with saline infusion sonography had a high sensitivity and high negative predictive value approaching $100 \%$. Our findings are in close agreement to the other studies as shown in Table 5. , $13-15$ Women with abnormal uterine bleeding who have failed medical management and found to have normal cavity during saline infusion sonography can avoid being subjected to further evaluation with the more invasive, expensive, and not easily available procedure of hysteroscopy in resource limited settings. Other advantages of saline infusion sonography are that it offers additional information about myometrium and adnexa. ${ }^{16}$ Therefore, in the absence of a hysteroscopy, saline infusion sonography offers an excellent choice in the evaluation of intrauterine abnormalities. 
Table 5: Diagnostic potential of SIS compared to hysteroscopy for detecting uterine intra-cavitary abnormalities.

\begin{tabular}{|llllll|} 
& $\begin{array}{l}\text { Our } \\
\text { study }\end{array}$ & $\begin{array}{l}\text { Rudra } \\
\text { et al. }^{8}\end{array}$ & $\begin{array}{l}\text { Widrich } \\
\text { et al. }^{12}\end{array}$ & $\begin{array}{l}\text { Krampl } \\
\text { et al. }^{13}\end{array}$ & $\begin{array}{l}\text { Kamel } \\
\text { et al. }^{14}\end{array}$ \\
\hline Sensitivity & $100 \%$ & $90.9 \%$ & $96 \%$ & $94 \%$ & $93.1 \%$ \\
\hline Specificity & $58.8 \%$ & $88.3 \%$ & $88 \%$ & $84 \%$ & $93.9 \%$ \\
\hline Positive predictive value & $82.5 \%$ & $86 \%$ & $89 \%$ & $89 \%$ & $94.6 \%$ \\
\hline Negative predictive value & $100 \%$ & $92.5 \%$ & $96 \%$ & $98 \%$ & $92 \%$ \\
\hline
\end{tabular}

The limitation of our study was that neither the patients nor the investigators were blinded about the findings. Small sample size and lack of correlation of findings with histopathology were also other limitations of our study.

\section{CONCLUSIONS}

Tranvaginal sonography is a routine procedure which is easily available for the evaluation of abnormal uterine bleeding; however the accuracy of transvaginal sonography in the diagnosis of focal endometrial lesions is limited. So, for the identification and assessment of uterine lesions, saline infusion sonography is a simple, safe, reliable, effective and well tolerated method without complications which compliments transvaginal sonography in the preoperative examination of uterine pathology. Besides these advantages the diagnostic potential and accuracy of saline infusion sonography makes it an excellent option in most hospitals where it can be performed easily and conveniently for evaluation of intrauterine abnormalities.

\section{Funding: No funding sources}

Conflict of interest: None declared

Ethical approval: The study was approved by the Hospital ethics committee

\section{REFERENCES}

1. Dubinsky TJ. Value of sonography in the diagnosis of abnormal vaginal bleeding. J Clin Ultrasound 2004;32:348-53.

2. de Kroon CD, Jansen FW. Saline infusion sonography in women with abnormal uterine bleeding: An update of recent findings. Curr Opin Obstet Gynecol. 2006;18:653-57.

3. Susanna I. An imaging algorithm for evaluation of abnormal uterine bleeding: does sonohysterography play a role? Menopause. 2007;14:823-5.

4. O'Connell LP, Fries MH, Zeringue E, Brehm W. Triage of abnormal postmenopausal bleeding: a comparison of endometrial biopsy and transvaginal sonohysterography versus fractional curettage with hysteroscopy. Am J Obstet Gynecol. 1998;178:95661

5. Abu-Ghazzeh Y, Shakoury WA, Barqawi R. Comparative study of transvaginal hysterosonography and biopsy for the evaluation of post-menopausal bleeding. Ann Saudi Med. 1999;19:116-9.

6. de Kroon CD, Jansen FW, Louwe LA, Dieben SW, van Houwelingen HC. Technology assessment of saline contrast hystersonography. Am J Obstet Gynecol. 2003;188:945-9.

7. Farquhar C, Ekeroma A, Furness S, Arroll B. A systematic review of transvaginal ultrasonography, sonohysterography and hysteroscopy for the investigation of abnormal uterine bleeding in premenopausal women. Acta Obstet Gynecol Scand. 2003;82:493-504.

8. Salim R, Lee C, Davies B, Jolaoso E, Ofuasia E, Jurkovic D. A comparative study of threedimensional saline infusion sonohysterography and diagnostic hysteroscopy for the classification of submucous fibroids. Hum Reprod. 2005;20:253-7.

9. Haemila FA, Youssef D, Hassan M, Soliman A, Mossad M. A prospective comparative study of 3-D ultrasonography and hysteroscopy in detecting uterine lesions in premenopausal bleeding. Middle East Fertil Soc J. 2005; 10:238-43.

10. Rudra S, Duggal BS, Bharadwaj D. Prospective study of saline infusion sonography and office hysteroscopy. Med J Armed Forces India. 2009;65:332-5.

11. Botsis D, Papagianni V, Makrakis E, Aravantinos L, Creatsas G. Sonohysterography is superior to transvaginal sonography for the diagnostic approach of irregular uterine bleeding in women of reproductive age. J Clin Ultrasound. 2006;34:434-9.

12. Dasgupta S, Chakraborty B, Karim R, Aich RK, Mitra PK, Ghosh TK. abnormal uterine bleeding in peri-menopausal age: diagnostic options and accuracy. J Obstet Gynecol India. 2011;61:189-94.

13. Widrich T, Bradley LD, Mitchinson AR, Collins RI. Comparison of saline infusion sonography with office hysteroscopy for the evaluation of endometrium. Am J Obstet Gynecol. 1996;174:132734.

14. Krampl E, Bourne T, Hurlen-Solbakken H, Istre O. Transvaginal ultrasonography, sonohysterography and operative hysteroscopy for the evaluation of abnormal uterine bleeding. Acta Obstet Gynecol Scand. 2001;80:616-22.

15. Kamel HS, Darwish AM, Mohamed SA. Comparison of transvaginal ultrasonography and vaginal sonohysterography in the detection of endometrial polyp. Acta Obstet Gynecol Scand. 2000;79:60-4. 
16. Mihm LM, Quick VA, Brumfield JA, Connors AF Jr, Finnerty JJ. The accuracy of endometrial biopsy and saline sonohysterography in the determination of the cause of abnormal uterine bleeding. Am J Obstet Gynecol. 2002;186:858-60.

DOI: $10.18203 / 2320-1770$. ijrcog20150101

Cite this article as: Nallapati S, Pallavee P, Ghose S. Comparative study of saline infusion sonography and hysteroscopy for evaluation of uterine cavity in abnormal uterine bleeding. Int J Reprod Contracept Obstet Gynecol 2015;4:828-32. 